\title{
A Method for the Evaluation of the Quality of Games for Computing Education
}

\author{
Giani Petri $^{1,2}$ (autor), Christiane Gresse von Wangenheim² (orientadora) \\ ${ }^{1}$ Universidade Federal de Santa Maria (UFSM) - Santa Maria, RS - Brasil \\ ${ }^{2}$ Programa de Pós-Graduação em Ciência da Computação (PPGCC), Departamento de \\ Informática e Estatística (INE), Universidade Federal de Santa Catarina (UFSC) - \\ Florianópolis, SC - Brasil \\ gpetrieinf.ufsm.br, c.wangenheimeufsc.br
}

\begin{abstract}
Educational games have been used as an instructional strategy expecting to contribute to students' learning, motivation, engagement, etc. However, in order to confirm these expected benefits, it is important to systematically evaluate such games. In this regard, the objective of this research is to develop and evaluate an evaluation method (MEEGA+) providing comprehensive support for evaluations of games used for computing education. The MEEGA+ method has been systematically developed and evaluated following a rigorous research methodology. Results of a reliability and validity analysis, as well as based on perspective of 19 experts in educational games, indicate that the MEEGA+ is a valid and reliable method and provides systematic support for game evaluations. It can be used by game creators, instructors and researchers in order to evaluate games as a basis for their improvement and effective and efficient adoption in practice for computing education.
\end{abstract}

\section{Introduction}

In the last years, games have been widely used as an instructional strategy in educational contexts in diverse knowledge areas such as mathematics, science, computing, health, and nutrition [Connolly et al., 2012; Battistella and Gresse von Wangenheim, 2016]. Educational games are designed to teach people about a certain subject, expand concepts, reinforce development, or assist learners in learning a skill or change an attitude [Djaouti et al., 2011]. Games are expected to provide a fun and safe environment, where students can try alternatives and see the consequences, learning from their own mistakes and practical experiences [Djaouti et al., 2011].

Especially in computing education, games have been used as an active instructional strategy in order to provide more practical learning opportunities to computing students [Kosa et al., 2016; Battistella and Gresse von Wangenheim, 2016]. Most of them are digital games, principally PC (Personal Computer) games, with a considerable trend also to non-digital ones (paper \& pencil, board games, etc.). Predominant are simulation games, which allow students to practice competencies through the simulation of real-life situations [Battistella and Gresse von Wangenheim, 2016]. On the other hand, there also are several games designed to teach computing aiming at learning objectives at lower cognitive levels. Typically, they are used to review 
and reinforce knowledge taught beforehand using different instructional strategies [Battistella and Gresse von Wangenheim, 2016].

In this context, games are supposed to be an effective and efficient instructional strategy for computing education. However, in practice, the expected benefits of this kind of games are still questionable due to a lack of studies providing evidence of these benefits [Connolly et al., 2012; Kosa et al., 2016; Petri and Gresse von Wangenheim, 2017]. Therefore, it is essential to systematically evaluate such games in order to obtain sound evidence of their quality.

As result of literature reviews analysing the state of the art and the practice [Petri and Gresse von Wangenheim, 2016; Petri and Gresse von Wangenheim, 2017], we identified that a reason for the lack of evidence of games' benefits may be that most games used for computing education are evaluated without explicitly defining an evaluation objective, research design, measurement, data collection instruments, and/or data analysis methods. This lack of scientific rigor leaves the reliability and validity of their results and, thus, the quality and/or effectiveness of such games questionable.

Another reason may be that there are only a few approaches that provide support for game evaluations [Petri and Gresse von Wangenheim, 2016]. Existing approaches to game evaluations, e.g., MEEGA (Model for the Evaluation of Educational Games) [Savi et al., 2011] and the EGameFlow scale [Fu et al., 2009], do not provide a comprehensive support to guide game evaluations. Currently, the MEEGA model is widely used for game evaluations in practice [Calderón and Ruiz, 2015]. Yet, although initially acceptable reliability has been identified, a more comprehensive analysis of the MEEGA model based on a series of case studies with 723 students indicated some improvement opportunities regarding its validity [Petri et al., 2017]. These improvement opportunities are related to an overlap of theoretical concepts of its quality factors motivation and user experience, as well as a lack of understanding of the wording of some questionnaire items [Petri et al., 2017]. Thus, evaluations using the MEEGA model may lead to imprecise results on the game's quality, not correctly identifying evidence of their benefits regarding the overlapped concepts. This, consequently, may impair the effective and efficient adoption of games as an instructional strategy for computing education as well as misguide their development and/or improvement. In addition, the existing approaches, including MEEGA, do not provide a more comprehensive support, for example, defining a process step by step in order to guide researchers in the planning, execution, and analysis of game evaluations [Petri and Gresse von Wangenheim, 2016]. Therefore, there is a lack of a valid and reliable method that provides a systematic and comprehensive support for the definition, execution, and analysis of game evaluations used for computing education.

Thus, the question focused on this research is: how to systematically conduct a quality evaluation of educational games used as an instructional strategy for computing education? In order to answer this question, the main contribution of this research is the design and evaluation of a new method (MEEGA+) improving the initial version of the MEEGA model and providing comprehensive support for game evaluations.

\section{Research Method}

In order to develop the MEEGA+ method, a multi-method research is adopted:

Step 1. Identify the state-of-the-art \& practice. In order to identify the state-ofthe-art and practice, we performed two systematic mapping studies. The state-of-the-art 
aims at identifying existing approaches (methods, models, frameworks, scales) to systematically evaluate educational games [Petri and Gresse von Wangenheim, 2016]. And, the state-of-the-practice, aims at identifying how games used for computing education are evaluated in practice [Petri and Gresse von Wangenheim, 2017].

Step 2. Conduct a large-scale evaluation of the initial version of a prominent evaluation approach. In order to better understand the shortcomings of existing approaches, we conduct a large-scale evaluation of the MEEGA model, currently the most used one in practice in this context. Following the case study approach as proposed by Yin (2017), the study objective has been defined and decomposed into quality aspects and analysis questions. In the execution phase, we collected data from the selected studies that evaluated educational games using the initial version of the MEEGA model, then we pooled the data collected in a single sample for data analysis. In the analysis phase, the data collected were analyzed in order to identify the reliability and construct validity of the prominent evaluation approach.

Step 3. Design the MEEGA+ model. The MEEGA+ model has been developed, as an evolution of the initial version of the MEEGA model [Savi et al., 2011] identified as a prominent evaluation approach, widely used in practice for game evaluations [Petri and Gresse von Wangenheim, 2016; Petri and Gresse von Wangenheim, 2017] and the large-scale analysis of the initial version of the MEEGA model [Petri et al., 2017]. The design of the MEEGA+ model follows the procedure of the scale development guide proposed by DeVellis (2016), defining an evaluation model, a standardized measurement instrument, the data analysis process, and the game quality scale.

Step 4. Design the MEEGA+ process. The MEEGA+ process aims to provide a systematic support, guiding researchers and instructors, in the conduction of game evaluations adopting the MEEGA+ model. The process is modeled in a prescriptive way following the approach proposed by Acuña and Ferré (2001), defining how the process should be performed, establishing phases, activities, and work products.

Step 5. Apply and evaluate the MEEGA+ method. The evaluation of the MEEGA+ method has been performed in two substeps. The first substep aims to evaluate the reliability and validity of the MEEGA+ model. In this substep, a series of case studies [Yin, 2017] are conducted, data are collected, grouped and analyzed in order to identify the reliability and validity of the MEEGA+ model. The second substep aims to evaluate the quality of the MEEGA+ method from the experts' perspective in terms of authenticity, validity, usability, correctness, completeness, consistency, understandability, unambiguousness, and flexibility, through an expert panel. The evaluation is defined and decomposed into analysis questions and metrics, which are collected through a questionnaire answered by experts in educational games after analyzing the MEEGA+ method.

\section{State of the Art and Practice}

In order to identify the state of the art on how to systematically evaluate educational games and the state of the practice on how educational games for computing education are evaluated, we conducted two systematic mapping studies [Petri and Gresse von Wangenheim, 2016; Petri and Gresse von Wangenheim, 2017].

Analyzing the state-of-the-art (articles published between 1995 and 2018) and the state of the practice (articles published between 1995 and 2015) we identified that there 
are only a few approaches, which provide systematic support for game evaluations. Most of them are frameworks rather than comprehensive evaluation methods [Freitas and Oliver, 2006; Connolly et al., 2009; Carvalho, 2012; Chew, 2017; Abdellatif et al., 2018]. Typically, these frameworks define a set of criteria ranging from the pedagogical perspective to gaming perspective, including context, environment, learner specifications, preferences, gameplay, user experience, etc. [Freitas and Oliver, 2006; Connolly et al., 2009; Carvalho, 2012]. However, the frameworks itself do not provide guidance on how to conduct the evaluation, data collection, and analysis.

In this regard, the works presented by $\mathrm{Fu}$ et al. (2009) and $\mathrm{Ak}$ (2012) propose scales providing instruments (questionnaires) to measure the quality of the games. However, only the EGameFlow scale [Fu et al., 2009] has been evaluated analyzing its validity and reliability as an instrument to evaluate the level of enjoyment provided by elearning games to their users. On the other hand, no evaluation of the scale proposed by Ak (2012) has been encountered, thus, leaving its validity and reliability questionable.

In summary, analyzing the state-of-the-art, we observe a lack of systematic, valid, and reliable approaches used for the evaluation of games that cover both the learning assessment and the evaluation of important aspects to provide a positive and engaging player experience. Therefore, based on these results, it becomes obvious that there exists a need for the identification of more consistent and uniform patterns to systematically evaluate educational games in order to obtain valid results that can be used to as a basis for a decision on the application of such games and/or their continuous improvement.

Consistent with this result, is the analysis of the state of the practice, indicating that most games used for computing education are evaluated without explicitly defining an evaluation objective, research design, measurement program, data collection instruments, and data analysis methods [Calderón and Ruiz, 2015; Kosa al., 2016; Petri and Gresse von Wangenheim, 2017]. And, often, data are collected only through students' informal comments and/or through questionnaires developed in an ad-hoc manner. Therefore, this lack of scientific rigor leaves the reliability and validity of their results and, thus, the quality and/or effectiveness of such games questionable [Calderón and Ruiz, 2015; Petri and Gresse von Wangenheim, 2017].

In this context, one approach for game evaluations stands out: the MEEGA model [Savi et al., 2011], being the only one evaluation approach that has been exclusively developed for computing education. In addition, the MEEGA model is widely used in practice for game evaluations, been reported by several studies from different authors evaluating different games, confirming also the findings of Calderón and Ruiz (2015). Therefore, we identified the MEEGA model [Savi et al., 2011] as a prominent approach to the evaluation of educational games. Thus, in this study, we adopted the initial version of the MEEGA model as the basis of our research.

\section{The MEEGA+ Method}

The MEEGA+ method (Figure 1) aims to provide systematic and comprehensive support for the evaluation of the quality of games used for computing education. It is composed of an evaluation model (MEEGA+ Model) defining quality factors to be evaluated through a standardized measurement instrument, a scale, which classifies the evaluated game according to its quality level, and a process (MEEGA+ Process), defining phases, 
VIII Congresso Brasileiro de Informática na Educação (CBIE 2019)

Anais dos Workshops do VIII Congresso Brasileiro de Informática na Educação (WCBIE 2019)

activities and work products, describing how to plan, execute and analyze the results of game evaluations.

\begin{tabular}{|l|l|}
\hline \multicolumn{2}{|c|}{ MEEGA+ Method } \\
\hline MEEGA+ Model & MEEGA+ Process \\
\cline { 2 - 2 } - Objective & - Scoping \\
- Quality factors & - Planning \\
- Research design & - Execution \\
- Questionnaires & - Analysis \\
- Analysis spreadsheets & - Presentation \\
\hline
\end{tabular}

Figure 1 - The MEEGA+ method

\subsection{MEEGA+ Model}

The MEEGA+ model aims to evaluate the quality of educational games in terms of usability and player experience from the students' perspective [Petri et al., 2018]. Based on the results of the literature reviews [Petri and Gresse von Wangenheim, 2016; Petri and Gresse von Wangenheim, 2017] and results of a preliminary statistical analysis of the MEEGA+ model (exploratory factor analysis), analysing a sample of 718 students from 40 case studies [Petri et al., 2018], the MEEGA+ model is decomposed into two quality factors (usability and player experience) and their dimensions (Table 1). We define usability as the degree to which a product (educational game) can be used by specified users (students) to achieve specified goals with effectiveness and efficiency in a specified context of use (computing education), being composed of the following dimensions: aesthetics, learnability, operability, and accessibility. Player experience is a quality factor that covers a deep involvement of the student in the gaming task, including his/her perception of learning, feelings, pleasures, and interactions with the game, environment, and other players, being composed of the following dimensions: focused attention, fun, challenge, social interaction, confidence, relevance, satisfaction, and perceived learning.

Research Design. In order to conduct the game evaluation in a quick and nonintrusive way, not interrupting the normal flow of the class and to not impair the participants involved in the study, a case study design is chosen for the evaluation that allows in-depth research of an individual, group or event. Thus, the evaluation is conducted adopting a one-shot post-test only design, in which the case study begins with the application of the treatment (educational game) and then a measurement instrument is answered by the students (self-assessment) in order to collect data on their perceptions about the game.

The MEEGA+ measurement instrument. Data collection is operationalized through a measurement instrument (questionnaire) (Table 1). The measurement instrument items are derived based on the defined quality factors/dimensions, customizing and unifying existing standardized questionnaires found in literature. The MEEGA+ measurement instrument is composed of 31 items that systematically measure the defined quality factors/dimensions. As response format, we adopt a 5-point Likert scale with response alternatives ranging from strongly disagree to strongly agree. Table 1 shows the items of the MEEGA+ measurement instrument for each quality factor/dimension. 
VIII Congresso Brasileiro de Informática na Educação (CBIE 2019)

Anais dos Workshops do VIII Congresso Brasileiro de Informática na Educação (WCBIE 2019)

Table 1 - MEEGA+ measurement instrument items

\begin{tabular}{|c|c|c|c|}
\hline $\begin{array}{l}\text { Quality } \\
\text { factor }\end{array}$ & Dimension & $\begin{array}{l}\text { Item } \\
\text { No. }\end{array}$ & Description \\
\hline \multirow{9}{*}{ 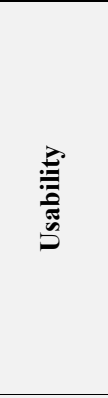 } & \multirow{2}{*}{ Aesthetics } & 1 & The game design is attractive (interface, graphics, cards, boards, etc.). \\
\hline & & 2 & The text font and colors are well blended and consistent. \\
\hline & \multirow{3}{*}{ Learnability } & 3 & I needed to learn a few things before I could play the game. \\
\hline & & 4 & Learning to play this game was easy for me. \\
\hline & & 5 & I think that most people would learn to play this game very quickly. \\
\hline & \multirow{2}{*}{ Operability } & 6 & I think that the game is easy to play. \\
\hline & & 7 & The game rules are clear and easy to understand. \\
\hline & \multirow{2}{*}{ Accessibility } & 8 & The fonts (size and style) used in the game are easy to read. \\
\hline & & 9 & The colors used in the game are meaningful. \\
\hline \multirow{22}{*}{ 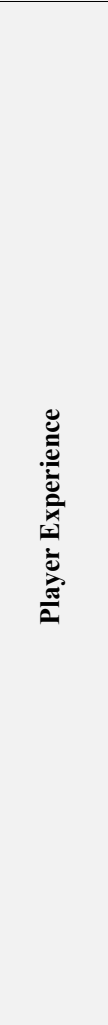 } & Confidence & 10 & The contents and structure helped me to become confident that I would learn with this game. \\
\hline & \multirow{3}{*}{ Challenge } & 11 & This game is appropriately challenging for me. \\
\hline & & 12 & $\begin{array}{l}\text { The game provides new challenges (offers new obstacles, situations or variations) at an } \\
\text { appropriate pace. }\end{array}$ \\
\hline & & 13 & The game does not become monotonous as it progresses (repetitive or boring tasks). \\
\hline & \multirow{4}{*}{ Satisfaction } & 14 & Completing the game tasks gave me a satisfying feeling of accomplishment. \\
\hline & & 15 & It is due to my personal effort that I managed to advance in the game. \\
\hline & & 16 & I feel satisfied with the things that I learned from the game. \\
\hline & & 17 & I would recommend this game to my colleagues. \\
\hline & \multirow{3}{*}{$\begin{array}{l}\text { Social } \\
\text { Interaction }\end{array}$} & 18 & I was able to interact with other players during the game. \\
\hline & & 19 & The game promotes cooperation and/or competition among the players. \\
\hline & & 20 & I felt good interacting with other players during the game. \\
\hline & \multirow[b]{2}{*}{ Fun } & 21 & I had fun with the game. \\
\hline & & 22 & $\begin{array}{l}\text { Something happened during the game (game elements, competition, etc.) which made me } \\
\text { smile. }\end{array}$ \\
\hline & \multirow{3}{*}{$\begin{array}{l}\text { Focused } \\
\text { Attention }\end{array}$} & 23 & There was something interesting at the beginning of the game that captured my attention. \\
\hline & & 24 & I was so involved in my gaming task that I lost track of time. \\
\hline & & 25 & I forgot about my immediate surroundings while playing this game. \\
\hline & \multirow{4}{*}{ Relevance } & 26 & The game contents are relevant to my interests. \\
\hline & & 27 & It is clear to me how the contents of the game are related to the course. \\
\hline & & 28 & This game is an adequate teaching method for this course. \\
\hline & & 29 & I prefer learning with this game to learning through other ways (e.g. other teaching methods). \\
\hline & \multirow{2}{*}{$\begin{array}{l}\text { Perceived } \\
\text { Learning }\end{array}$} & 30 & The game contributed to my learning in this course. \\
\hline & & 31 & The game allowed for efficient learning compared with other activities in the course. \\
\hline
\end{tabular}

Data Analysis. Data collected in the evaluations using the MEEGA+ measurement instrument are analyzed in terms of frequency distribution (through frequency graphs) and central tendency (median) for each quality factor (usability and player experience) and their dimensions. The MEEGA+ model provides a spreadsheet for analysis of the data collected, assisting in the organization of the information and automatic generation of graphs, visualizing the results of the evaluation.

Game quality scale. The scale aims to classify the evaluated game on a quality level. The scale has been developed by adopting the Item Response Theory, which allows to express through mathematical models the relationship between observable variables (questionnaire items) and latent traits (game quality). Based on the results of the analysis, three quality levels are defined to classify the game: low, good, and excellent quality.

The complete material of the MEEGA+ method is available in English, Brazilian Portuguese and Spanish at: http://www.gqs.ufsc.br/meega-a-model-for-evaluatingeducational-games/ under the Creative Commons License. 
VIII Congresso Brasileiro de Informática na Educação (CBIE 2019)

Anais dos Workshops do VIII Congresso Brasileiro de Informática na Educação (WCBIE 2019)

\subsection{MEEGA+ Process}

In order to guide the application of the model, the MEEGA+ method contains a systematic process. The process specifies steps, activities and work products, guiding researchers and instructors in the conduction of game evaluations. The MEEGA+ process is organized into five phases: scoping, planning, execution, analysis, and presentation, as presented in Figure 2.

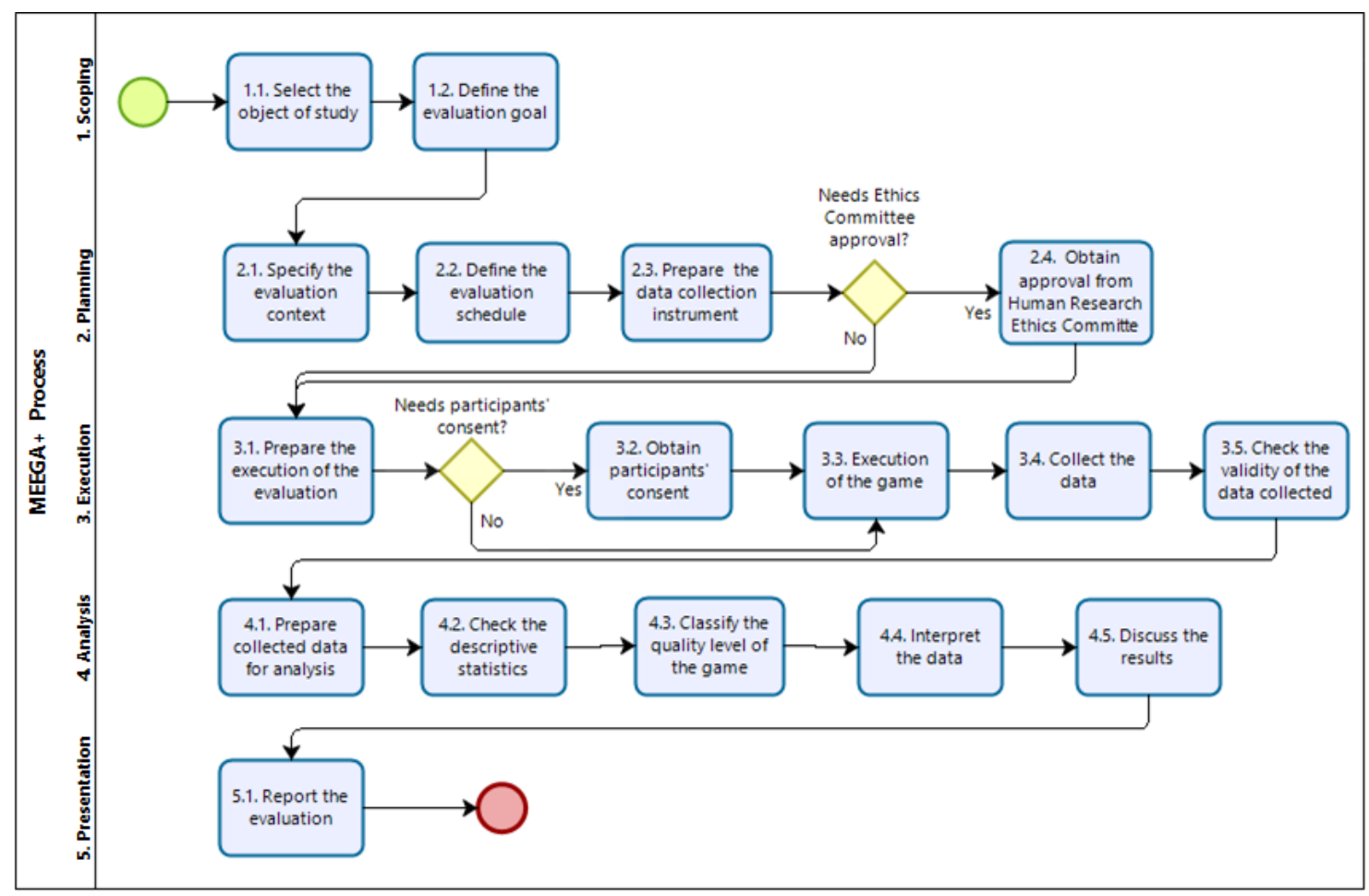

Figure 2 - The MEEGA+ process

\section{Application and Evaluation of the MEEGA+ Method}

The evaluation of the MEEGA+ method is performed in two steps. The first step aims to evaluate the reliability and validity of the measurement instrument of the MEEGA+ model based on data collected through a series of case studies conducted. The second step aims to evaluate the quality of the MEEGA+ method based on the experts' perspective.

\subsection{Evaluation of the MEEGA+ Model}

The objective of this evaluation is to analyze the MEEGA+ measurement instrument in order to evaluate its reliability and construct validity from the viewpoint of researchers in the context of computing education. Results of this study are interpreted from the researchers' perspective, the researchers are members of the Software Quality Group (GQS/INCoD/INE/UFSC), with backgrounds in computing and statistics.

From July 2016 to July 2018, we conducted a series of 62 case studies evaluating 24 different educational games used for computing education. In each of these case studies, the MEEGA+ measurement instrument was used after the game session (treatment) in order to collect the students' perceptions about the game. In total, we collected responses from 1048 students in eight different educational institutions in Brazil and Spain. 
Results of the reliability analysis indicate an excellent internal consistency of the MEEGA+ measurement instrument (Cronbach's alpha $\alpha=.927$ ). Results of the validity analysis, through an exploratory factor analysis and items correlation, confirm the original structure of the MEEGA+ model, indicating that the quality of games for computing education is evaluated in terms of usability and player experience.

\subsection{Evaluation of the MEEGA+ Method}

The objective of this evaluation is to analyze the MEEGA+ method in order to evaluate its quality in terms of correctness, authenticity, consistency, understandability, unambiguousness, completeness, flexibility, validity, and usability, from the viewpoint of experts in educational games in the context of computing education. Based on this objective, analysis questions and metrics are defined for each quality characteristic. In order to collect data on the defined quality characteristics based on the experts' perspective, we conducted an expert panel [Beecham et al., 2005]. As research strategy we conducted a survey, the most suitable strategy for collecting information from people about a new method [Wohlin et al., 2012]. A questionnaire was defined as the data collection instrument, as it is best suited to the nature and type of data that we need to analyze [Beecham et al., 2005]. The questionnaire items are determined based on the defined quality characteristics and metrics.

The expert panel was conducted in August and September 2018. We define an expert, in the context of this study, as a person who has a Ph.D. or is a Ph.D. student in any knowledge area with scientific publications in recognized Brazilian and/or international journals and/or conferences in the field of educational games. We invited 34 experts to participate in the evaluation of the MEEGA+ method. All experts were personally invited by sending a private e-mail containing the technical report describing the MEEGA+ method and the questionnaire online as Google Forms. In total, 19 experts accepted and answered the questionnaire completely (representing a response rate of $56 \%$ ).

The results based on the opinion of 19 experts in the area of educational games, provide a first indication that the MEEGA+ method is valid, authentic, correct, complete, understandable, unambiguous, consistent, flexible, and has good usability. However, some inconsistencies, misunderstood items, and suggestions have been reported by experts, being most of them corrected in the current version of the MEEGA+ method. Therefore, based on the results of the expert panel and considering the strengths reported by the experts, we can observe several indications that the MEEGA+ method achieves its objective, providing systematic and comprehensive support for quality evaluation of games used as an instructional strategy for computing education.

\section{Scientific Publications}

During the development of this research, partial results have been published as journal and conference papers, as well as book chapters. Table 2 presents the scientific publications produced in the context of this research. 
VIII Congresso Brasileiro de Informática na Educação (CBIE 2019)

Anais dos Workshops do VIII Congresso Brasileiro de Informática na Educação (WCBIE 2019)

Table 2 - Publications

\begin{tabular}{|c|c|c|}
\hline Id & Reference & $\begin{array}{l}\text { Qualis } \\
\text { Computer } \\
\text { Science }\end{array}$ \\
\hline 1 & $\begin{array}{l}\text { PETRI, G., \& GRESSE VON WANGENHEIM, C. (2017). How games for computing education are evaluated? A systematic } \\
\text { literature review, Computers \& Education, 107, pp. 68-90. DOI: https://doi.org/10.1016/j.compedu.2017.01.004 }\end{array}$ & A1 \\
\hline 2 & $\begin{array}{l}\text { PETRI, G., GRESSE VON WANGENHEIM, C., \& BORGATTO, A. F. (2017). A Large-scale Evaluation of a Model for the } \\
\text { Evaluation of Games for Teaching Software Engineering. In Proc. of the 39th International Conference on Software } \\
\text { Engineering (pp. 180-189). Buenos Aires/Argentina. DOI: https://doi.org/10.1109/ICSE-SEET.2017.11 }\end{array}$ & $\mathrm{A} 1$ \\
\hline 3 & $\begin{array}{l}\text { PETRI, G.; GRESSE VON WANGENHEIM, C.; BORGATTO, A. F. Quality of Games for Teaching Software Engineering: An } \\
\text { Analysis of Empirical Evidence of Digital and Non-digital Games. In Proc. of the 39th International Conference on Software } \\
\text { Engineering (pp. 150-159). Buenos Aires/Argentina. DOI: https://doi.org/10.1109/ICSE-SEET.2017.18 }\end{array}$ & $\mathrm{A} 1$ \\
\hline 4 & $\begin{array}{l}\text { PETRI, G., \& GRESSE VON WANGENHEIM, C. (2016). How to evaluate educational games: a systematic literature review. } \\
\text { Journal of Universal Computer Science, 22(7), pp. 992-1021. DOI: http://dx.doi.org/10.3217/jucs-022-07-0992 }\end{array}$ & B1 \\
\hline 5 & 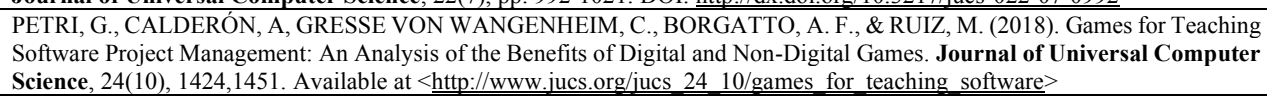 & B1 \\
\hline 6 & $\begin{array}{l}\text { PETRI, G., BATTISTELLA, P., CASSETTARI, F., GRESSE VON WANGENHEIM, C., \& HAUCK, J. (2016). Um Quiz Game } \\
\text { para a revisão de conhecimento em Gerenciamento de Projetos. In Proc. of the } \mathbf{2 7} \text { Simpósio Brasileiro de Informática na } \\
\text { Educação (SBIE) (pp. 320-329). Uberlândia/MG. DOI: http://dx.doi.org/10.5753/cbie.sbie.2016.320 }\end{array}$ & B1 \\
\hline 7 & $\begin{array}{l}\text { SOARES, R., PETRI, G., GRESSE VON WANGENHEIM, C., CONTE, T., \& MARQUES, A. B. (2018). AssistantMEEGA+: } \\
\text { Uma ferramenta de apoio para avaliação de jogos educacionais usando modelo MEEGA+. In Proc. of the 29 Simpósio Brasileiro } \\
\text { de Informática na Educação (SBIE), Fortaleza/CE. DOI: http://dx.doi.org/10.5753/cbie.sbie.2018.615 }\end{array}$ & B1 \\
\hline 8 & $\begin{array}{l}\text { BATTISTELLA, P. E., PETRI, G., GRESSE VON WANGENHEIM, C., VON WANGENHEIM, A., \& MARTINA, J. E. (2016). } \\
\text { SORTIA 2.0: Um jogo de ordenação para o ensino de Estrutura de Dados. In Proc. of the } \mathbf{1 2}{ }^{\circ} \text { Simpósio Brasileiro de Sistemas } \\
\text { de Informação (SBSI) (558-565). Florianópolis/SC. Available at }<\text { http://www.lbd.dcc.ufmg.br/colecoes/sbsi/2016/073.pdf }>\end{array}$ & $\mathrm{B} 2$ \\
\hline 9 & $\begin{array}{l}\text { PETRI, G., GRESSE VON WANGENHEIM, C., \& BORGATTO, A. F. (2019). Um modelo para a avaliação de jogos } \\
\text { educacionais para o ensino de computação. Revista Brasileira de Informática na Educação. }\end{array}$ & B3 \\
\hline 10 & $\begin{array}{l}\text { PETRI, G., GRESSE VON WANGENHEIM, C., \& BORGATTO, A. F. (2017). Evolução de um Modelo de Avaliação de Jogos } \\
\text { para o Ensino de Computação. In Proc. of the 25 }{ }^{\circ} \text { Workshop sobre Educação em Computação (CSBC/WEI) (pp. 2327-2336). } \\
\text { São Paulo/SP. Available at }<\underline{\text { http://csbc2017.mackenzie.br/public/files/25-wei/25.pdf }>}\end{array}$ & B3 \\
\hline 11 & 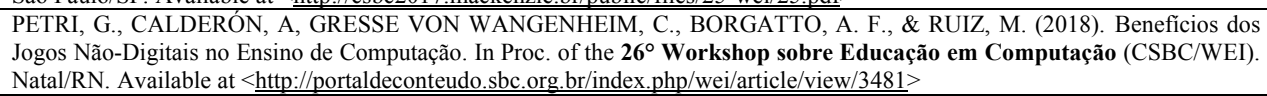 & B3 \\
\hline 12 & 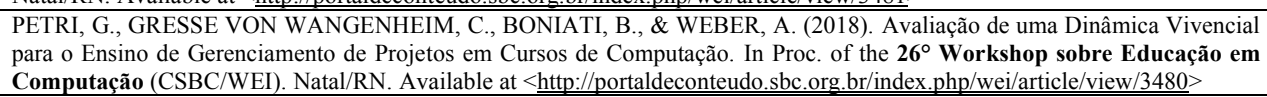 & $\begin{array}{l}\text { B3 } \\
\text { (honors } \\
\text { mention) }\end{array}$ \\
\hline 13 & $\begin{array}{l}\text { PETRI, G., GRESSE VON WANGENHEIM, C., \& BORGATTO, A. F. (2018). MEEGA+, Systematic Model to Evaluate } \\
\text { Educational Games. In: Lee N. (Eds.) Encyclopedia of Computer Graphics and Games (pp. 1-7). Springer. DOI: } \\
\text { https://doi.org/10.1007/978-3-319-08234-9 214-1 }\end{array}$ & Book chapter \\
\hline 14 & $\begin{array}{l}\text { PETRI, G., GRESSE VON WANGENHEIM, C., BORGATTO, A. F., CALDERÓN, A., \& RUIZ, M. (2018). Digital Games for } \\
\text { Computing Education: What are the Benefits? In: Krassmann et al. (Eds.) Handbook of Research on Immersive Digital Games } \\
\text { in Educational Environments. IGI Global. Chap 2. DOI: https://doi.org/10.4018/978-1-5225-5790-6.ch002 }\end{array}$ & Book chapter \\
\hline
\end{tabular}

\section{Conclusions}

As a result of this research, we develop and evaluate the MEEGA+ method, being a welldefined, valid and reliable method, providing a systematic and comprehensive support for quality evaluations of games used for computing education. Thus, answering our research question, indicating that one way to systematically evaluate games for computing education is adopting the MEEGA+ method. The list of publications and wide adoption of the MEEGA+ method by the community (as mentioned in thesis chapter 8), show that this thesis has provided a strong contribution to the state of the art, providing a systematic and comprehensive support for quality evaluations of games used for computing education and thus contributing to an effective and efficient teaching of computing in a fun way keeping students engaged and motivated.

Although the emphasis of the MEEGA+ is on the evaluation of games for computing education, we assume that the MEEGA+ method can be used and adapted for the evaluation of games to teach others knowledge areas. However, when transferring the method to other knowledge areas, further empirical studies are necessary to evaluate and confirm the reliability and validity of the MEEGA+ method also in these areas. 
VIII Congresso Brasileiro de Informática na Educação (CBIE 2019)

Anais dos Workshops do VIII Congresso Brasileiro de Informática na Educação (WCBIE 2019)

\section{References}

Abdellatif, A. J. et al. (2018). Serious Games: Quality Characteristics Evaluation Framework and Case Study. Proc. of the Integrated STEM Education Conference, Princeton, USA.

Acuña, S. T. and Ferré, X. (2001). Software Process Modelling. Proc. of the World Multiconference on Systemics, Cybernetics and Informatics, Orlando, USA.

Ak, O. (2012). A Game Scale to Evaluate Educational Computer Games. Procedia - Social and Behavioral Sciences, 46, 2477-2481.

Battistella, P. and Wangenheim, C. G. (2016). Games for Teaching Computing in Higher Education - A Systematic Review. IEEE Technology and Engineering Education Journal, 9(1), 8-30.

Beecham, S. et al. (2005). Using an Expert Panel to Validate a Requirements Process Improvement Model. Journal of Systems and Software, 76(3), 251-275.

Calderón A. and Ruiz M. (2015). A systematic literature review on serious games evaluation: An application to software project management. Computers \& Education, 87, 396-422.

Calderón A., Ruiz M., and O'connor, R. (2018). A multivocal literature review on serious games for software process standards education. Comp Standards \& Interfaces, 57, 36-48.

Carvalho, C. V. (2012). Is game-based learning suitable for engineering education? Proc. of the Global Engineering Education Conf., (pp.1-8). Marrakech, Morocco.

Chew, B. (2017). An efficient framework for game-based learning activity. Prof. of the Int. Conf. on Teaching, Assessment, and Learning for Engineering. Hong Kong, China.

Connolly, T. M. et al. (2009). Towards the development of a games-based learning evaluation framework. In T. M. Connolly, M. H. et al. (Eds.), Games-based learning advancement for multisensory human computer interfaces: Techniques and effective practices. Hershey: Idea-Group Publishing.

Connolly, T. M. et al. (2012). A Systematic Literature Review of Empirical Evidence on Computer Games and Serious Games. Computers \& Education, 59(2), 661-686.

DeVellis, R. F. (2016). Scale development: theory and applications. SAGE Publications.

Djaouti, D. et al. (2011). Origins of Serious Games. In: Ma M., Oikonomou A., Jain L. (Eds) Serious Games and Edutainment Applications. London: Springer.

Freitas, S. D., and Oliver, M. (2006). How can exploratory learning with games and simulations within the curriculum be most effectively evaluated? Computers \& Education, 46(3), 249-264.

Fu, F., Su, R., and Yu, S. (2009). EGameFlow: A scale to measure learners' enjoyment of e-learning games. In Computers \& Education, 52(1), 101-112.

Kosa, M. et al. (2016). Software engineering education and games: a systematic literature review. Journal of Universal Computer Science, 22 (12), 1558-1574.

Petri, G. and Gresse von Wangenheim, C. (2016). How to Evaluate Educational Games: a Systematic Literature Review. Journal of Universal Computer Science, 22(7), 992-1021.

Petri, G. and Gresse von Wangenheim, C. (2017). How games for computing education are evaluated: a systematic literature review. Computers \& Education, 107, 68-90.

Petri, G. et al. (2017). A large-scale evaluation of a model for the evaluation of games for teaching software engineering. Proc. of the 39th Int. Conf. on Software Engineering. Buenos Aires, Argentina.

Petri, G. et al. (2018). MEEGA+, Systematic Model to Evaluate Educational Games. In Newton Lee (Eds) Encyclopedia of Computer Graphics and Games. Cham: Springer.

Savi, R., Gresse von Wangenheim, C., and Borgatto, A. F. (2011). A Model for the Evaluation of Educational Games for Teaching Software Engineering. Proc. of the Brazilian Symposium on Software Engineering, São Paulo, Brazil.

Wohlin, C. et al. (2012). Experimentation in Software Engineering. Springer-Verlag Berlin Heidelberg.

Yin, R. K. (2017). Case study research and applications: design and methods (5 ed.). Sage Publications, Beverly Hills. 